\title{
Depth adjacency and the rod-and-frame illusion
}

\author{
WALTER C. GOGEL and ROBERT E. NEWTON \\ University of California, Santa Barbara, California 93106
}

\begin{abstract}
In Experiment I, the tactile adjustment of a comparison bar was used to measure the change in the rod-and-frame illusion as a function of the stereoscopic position of the rod relative to the frame. A vertical rod was presented at a near, a middle, or a far distance, with a single frame tilted counterclockwise at the near distance, a single frame tilted clockwise at the far distance, or two frames of opposite tilt presented simultaneously at the near and far distances. When only one frame was present, displacement of the rod in front of the far frame but not behind the near frame significantly reduced the illusion. When both frames were present, the illusion was determined mainly by the frame at the apparent distance of the rod. In Experiment II, the tactile method of measuring perceived tilt was validated for the range of perceived tilts encountered in Experiment I. The results of Experiment I are discussed in terms of the perceptual resolution of the conflict between relative and absolute cues of tilt.
\end{abstract}

An induction effect in perception is a modification of the perceived characteristics of one stimulus (the test object) by another stimulus (the induction object). It has been found in a number of studies, and for a number of different kinds of induction, that a stereoscopic separation of the test and induction object will modify the magnitude of the induction (Gogel, 1970, 1972, 1974, 1975; Gogel \& Koslow, 1971, 1972; Green, Lawson, \& Godek, 1972; Wist, 1974; Wist \& Susen, 1973). The purpose of the present study was to examine the effect of stereoscopic separation (perceived separation in depth) of the test and induction object upon the magnitude of the rod-and-frame illusion.

\section{EXPERIMENT I}

The design of Experiment $I$ of the present study is similar to that of a previous study using the Ponzo illusion (Gogel, 1974). In that study, as in the present study, either single induction objects or two induction objects of opposite orientation at different perceived distances were presented with the test object at one of three stereoscopic distances. The basic rod-and-frame illusion and the conditions used in Experiment I can be discussed with respect to Figure 1. The dashed rectangles enclosing the rod and frames are to maintain the perspective of the drawing for purposes of illustration and were not present during the study. Figure 1 illustrates a situation in which two frames are presented with three alternative positions of the rod. The near frame was physically tilted counterclockwise and the far frame was physically tilted clockwise from the vertical. The two frames

This investigation was supported by U.S. Public Health Service Research Grant MH 15651 from the National Institute of Mental Health. subtended the same visual angle and were presented either simultaneously or singly. Only one rod was presented at any time. The rod was always physically vertical, was stereoscopically presented at the near $(\mathrm{N})$, middle $(\mathrm{M})$, or far $(\mathrm{F})$ distance from the observer, and subtended a constant visual angle at each of these distances.

The basic rod-and-frame illusion usually is measured by having the observer adjust the rod to the apparent vertical (Asch \& Witkin, 1948; Beh, Wenderoth, \& Purcell, 1971; Witkin, 1959; Witkin \& Asch, 1948). The result of such an adjustment for physical tilts of the frame less than $45^{\circ}$ from the vertical is that the rod must be tilted (rotated) in the same direction as the physical tilt of the frame in order to appear vertical (Beh, Wenderoth, \& Purcell, 1971). It follows that the physically vertical rod of the present study should appear tilted in a direction opposite to the physical tilt of the frame. If only a rod

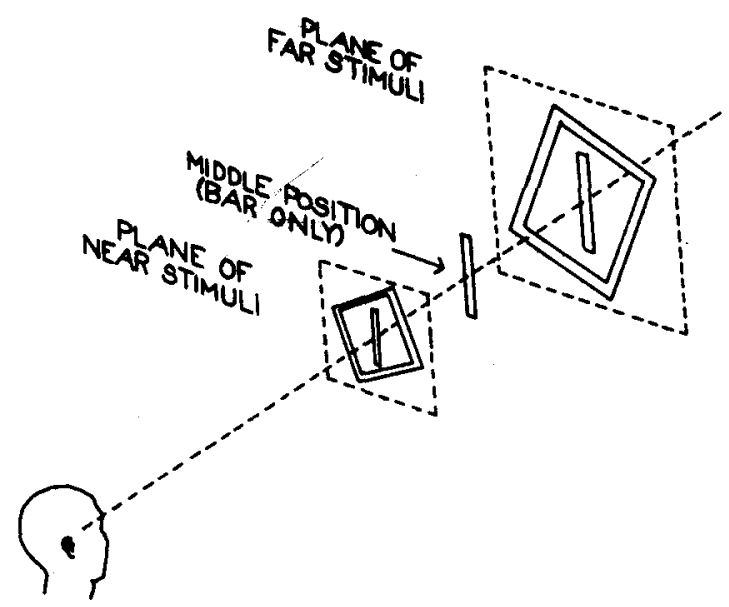

Figure 1. Perspective drawing illustrating two frames (induction objects) of opposite tilt with three alternative stereoscopic positions of the rod (test object). 


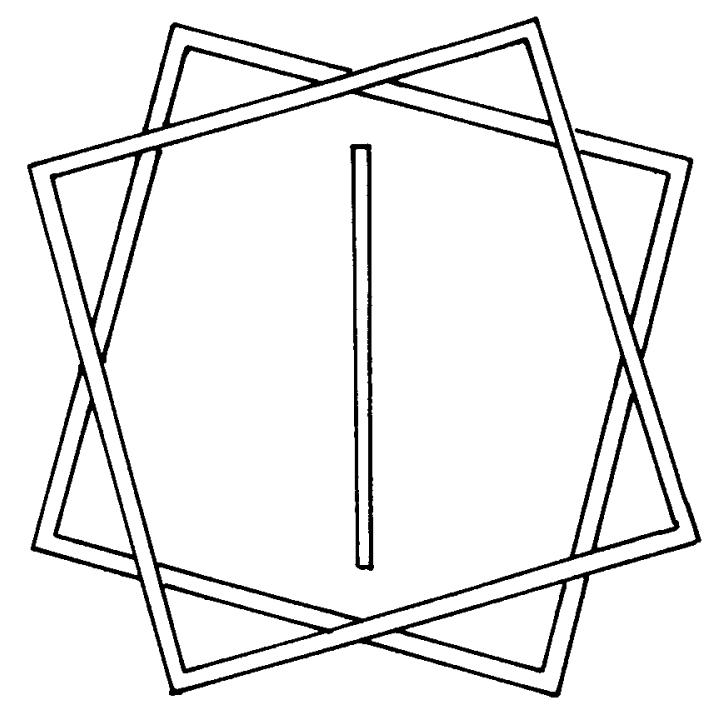

Figure 2. Projection on cyclopean eye of the situation illustrated in Figure 1.

and one frame were present in the situation of Figure 1, according to the rod-and-frame illusion the physically vertical rod should appear to be tilted clockwise for the physically counterclockwise tilt of the near frame, and should appear to be tilted counterclockwise for the physically clockwise tilt of the far frame.

Experiment I used three basic situations. (1) The near frame was the only frame present with the rod stereoscopically at the distance of this frame or behind this frame at the middle or far distance. (2) The far frame was the only frame present with the rod stereoscopically at the distance of this frame or in front of this frame at either the middle or the near distance. (3) The two frames of opposite tilt were presented simultaneously with the rod stereoscopically at the distance of the near frame, between the frames in depth, or at the distance of the far frame. If the stereoscopic depth between the rod and frame modifies the illusion, it follows that the illusion cannot be specified completely by the spatial relations of the stimulus defined at the retina or, equivalently, by the projection of the rod and frame on a frontoparallel plane. A view from the position of the observer of the rod and two frames of Figure 1 projected on a frontal plane midway between the two eyes (the cyclopean eye) is shown in Figure 2. If the perceived depth separation of the rod and frame were not an important factor, the rod-and-frame illusion would vanish in Situation 3 and would be constant for all stereoscopic positions of the rod in Situations 1 and 2.

Predictions concerning the effect of the stereoscopic separation of the rod and frame in the three situations can be derived from the adjacency principle and an analysis in terms of cue conflicts (also see Gogel, 1975). The adjacency principle states that the effectiveness of cues between objects (in this case, between the rod and frame) is inversely related to the perceived separation of these objects in either depth or direction. The cue conflict in the situations in which only one trame is present (Situations 1 and 2) is between two factors. One factor (a noninduction factor) is the cue or cues that would determine the apparent position of the rod in the absence of the tilted frame. If a physically vertical rod is the only object present in the visual field, it usually is perceived as vertical (Cohen \& Tepas, 1958; Neal, 1926). Thus, in the absence of a frame, there is a cue or cues which would tend to make the rod appear vertical. This will be called the absolute tilt cue for the rod. The other factor is the physical tilt of the frame (the induction factor) which would tend to make the physically vertical rod appear tilted in a direction opposite to the physical tilt of the frame. This will be called the relative tilt cue, and in the rod-and-frame illusion these two kinds of cues are in conflict. The effect on the rod-and-frame illusion of stereoscopically separating the rod from the frame will depend upon changes in the relative magnitude (strength) of these two kinds of cues as a function of stereoscopic separation. According to the adjacency principle, the strength of the relative tilt cue will decrease with an increase in the perceived separation of the rod either in front of or behind the frame. This decrease in the strength of the relative tilt cue will become manifest, however, only if it results in a decrease in the contribution of the relative tilt cue to the perception as compared to the contribution of the absolute tilt cue for the rod. Thus, the strength of the absolute tilt cue as a function of the convergence distance of the rod from the observer as well as the strength of the relative tilt cue as a function of the stereoscopic depth between the rod and frame must be considered if the results obtained from Situations 1 and 2 are to be understood.

If the strength of the absolute tilt cue for the rod is assumed to remain constant with modifications of the stereoscopic (convergence) distance of the rod in Situations 1 and 2, changes in the rod-and-frame illusion with increasing stereoscopic separation of the rod and frame will be determined solely by the changes in the relative tilt cue. According to the adjacency principle, the strength of the relative tilt cue will decrease with increasing perceived separation of the rod from the frame regardless of whether the rod is displaced perceptually behind or in front of the frame. In other words, perceptual displacement of the rod behind or in front of a frame by the same amount should produce the same decrease in the illusion only if the absolute tilt cue remains constant in strength during this process. If the strength of the absolute tilt cue decreases with increasing distance of the rod from the observer, displacement of the rod in front of the frame should produce a greater reduction in the 
illusion than a perceptually equal displacement of the rod behind the frame. On the other hand, if the strength of the absolute tilt cue is increased with increasing distance of the rod from the observer, the greater reduction in the illusion should occur with displacement of the rod behind rather than in front of the frame. In other words, to predict the details of the results obtained with stereoscopic displacement of the rod from the frame in Situations 1 and 2, it is necessary to measure the strength of the absolute tilt cue for the rod as a function of the convergence distance of the rod from the observer. In the present study, this will be measured by comparing the magnitude of the illusion obtained in Situations 1 and 2 for the two conditions in which the rod is at the same stereoscopic distance as the frame. Since these two conditions provide the same relative tilt cue but different values of convergence, the comparison of the illusion obtained from these conditions will indicate changes in the strength of the absolute tilt cue as a function of the convergence to the rod. In this comparison, it will be assumed that the absolute magnitude of the rod-and-frame illusion is the same for equal clockwise and counterclockwise tilts of the frame. This assumption in general is consistent with the results obtained from the study by Beh, Wenderoth, and Purcell (1971).

Consider the case in which two frames are presented simultaneously at opposite physical tilts (Situation 3). It is expected, from the adjacency principle. that the induction effect of a particular frame on the perceived tilt of the rod will increase relative to that from the other frame as the rod is increasingly closer to the first frame in depth. Thus, the physically vertical rod should be perceived as tilted clockwise when it is in the plane of the near frame, as tilted counterclockwise when it is in the plane of the far frame, and as between these perceptions when it is stereoscopically between the two frames in perceived depth.

To summarize: The primary purpose of this study is to demonstrate that the rod-and-frame illusion can be modified by the stereoscopic separation of the test and induction object as has been found for several other induction effects. A second purpose (if this modification occurs) is to explain the stereoscopic effect in terms of a cue conflict between absolute and relative cues of tilt. Changes in the strength of the relative tilt cue with changes in the perceived depth between the rod and frame will be assumed to follow the adjacency principle. Changes in the absolute tilt cue as a function of the convergence of the rod from the observer will be determined by using the conditions in which the rod and frame are at the same stereoscopic distance. The magnitude of the illusion under these conditions will be measured as a function of the convergence of the entire display from the observer. The results from this analysis will be used together with the adjacency principle to explain the symmetrical or asymmetrical modification in the illusion as a consequence of crossed or uncrossed disparity between the rod and frame.

\section{Method}

Apparatus. The rod-and-frame figures were luninous objects produced by fluorescent surfaces, appropriately masked. The visual angular sizes of the sides of the near or far square frames were $10^{\circ} 19.2^{\prime}$, with $0^{\circ} 21.6^{\prime}$ the width of the line forming each side. The frames were tilted from the vertical about their centers. The near frame was physically located at $100 \mathrm{~cm}$ from the observer and was always tilted $15^{\circ}$ counterclockwise from the vertical. The far frame was physically located at $160 \mathrm{~cm}$ and was always tilted $15^{\circ}$ clockwise from the vertical. The rod was always physically vertical and was located stereoscopically at 100,123 , or $160 \mathrm{~cm}$ from the observer. The visual angle of the height and width of the rod was always $8^{\circ} 34^{\prime}$ and $0^{\circ} 21.3^{\prime}$, respectively.

The method of presenting the several stimuli is shown in the top-view drawings of Figures 3 and 4 . The frames at the near $(100 \mathrm{~cm})$ or far $(160 \mathrm{~cm})$ distance were viewed binocularly by means of two partially reflecting. partially transmitting mirrors. The rod, also viewed binocularly, was physically at the middle distance $(123 \mathrm{~cm})$ from the observer and could be presented stereoscopically (using the Polaroid stereoscope diagramed in Figure 4) at the near $(100 \mathrm{~cm})$, middle $(123 \mathrm{~cm})$, or far $(160 \mathrm{~cm})$ distance from the

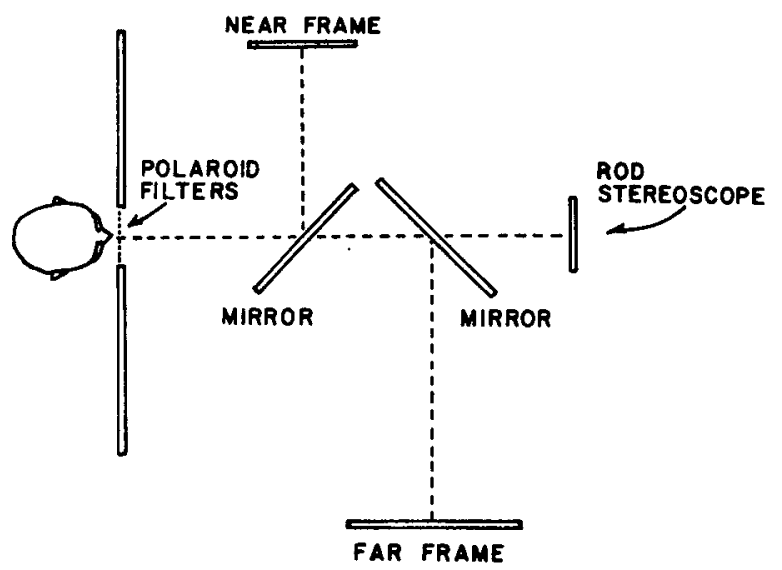

Figure 3. Schematic top-view drawing of the apparatus for producing the near and far frame and three stereoscopic positions of the rod.

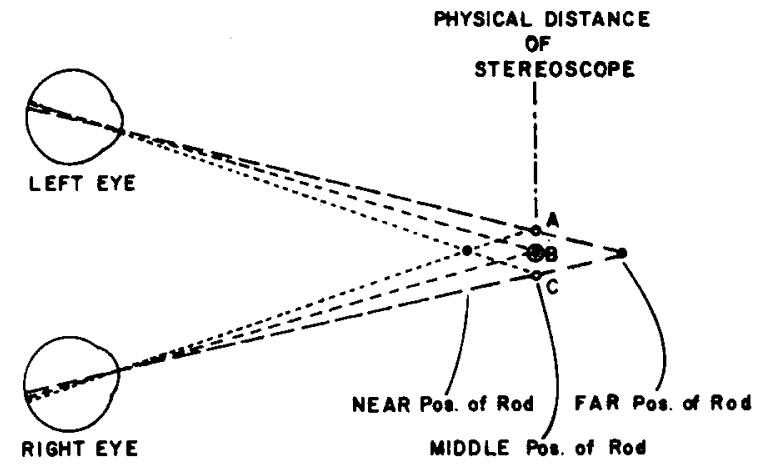

Figure 4. Schematic top-view drawing of the Polaroid stereoscope producing the three stereoscopic positions of the rod. 
observer (assuning an internodal eye distance of $6.2 \mathrm{~cm}$ ). The near and far stereoscopic distances of the rod were produced by means of two sets of orthogonally oriented Polaroid filters with one set located at the plane of the stereoscope and the other set at the observation position. The orientation of the Polaroids at the observer's eyes could be reversed by the experimenter from a location outside the observation booth by a slide which positioned one of two pairs of Polaroids in front of the observer's eyes. The method of presenting the rod at the different stereoscopic distances is show $n$ in Figure 4 . Three lu minous vertical rods, identical in size and shape (labeled $A$ through $C$ in Figure 4), were produced by tigures physically in the plane of the stereoscope. For the near and far stereoscopic distance of the rod, A and B in Figure 4 were viewed through different sets of orthogonal Polaroids. To produce the rod at the near distance, A was seen with the right eye only and $C$ with the left eye only. To produce the rod at the far distance, $C$ was seen with the right eye only and $A$ with the left eye only. To produce the rod at the middle distance. $B$ was viewed binocularly without Polaroids (through neutral density filters) and was both physically and stereoscopically at the plane of the stereoscope. The brightness of the rod and frames was $.16 \mathrm{fL}$, as measured from the observation position. Since the accommodative distance of the rod was always to $123 \mathrm{~cm}$, the accommodative difference in diopters between a rod and a square frame was always the same (about $.2 \mathrm{D})$, although opposite in direction with respect to the near and far frames. The stereoscopic differences between the near and far stimulus positions (of rod or frames) was $80^{\prime}$ of binocular disparity, with the middle position of the rod $40^{\prime}$ behind and in front of the near and far position, respectively. The near frame and the far frame could be turned on and off independently, permitting, with each of the three alternative stereoscopic positions of the rod, the presentation of the near frame only, the far frame only, or both frames simultaneously.

The stimuli were viewed from a booth that was totally dark during the observations. A lighted circular surface, $20.5 \mathrm{~cm}$ in diam with a brightness of $26.0 \mathrm{fL}$, was located to the side of the observer in order to light-adapt the observer before beginning the experiment and between presentations of the experimental conditions. The stimuli were viewed through a circular aperture, the edges of which were invisible to the observer during the experiment and which was occluded by the experimenter between stimulus presentations by closing a shutter. The visual field was entirely dark except for the luminous lines of the square frame or frames and the rod. During the experiment, the experimenter and the observer communicated by means of headphones and microphones. White noise was presented in the headphones between trials to mask any sounds made by the experimenter.

In addition to the viewing aperture, the observation position contained an adjustable stool, an adjustable head and chin rest. the slide for the Polaroids, and a device located to the right and slightly above the observer's waist by means of which the observer could indicate the apparent orientation of the rod and the frames. This device was a round metal bar (a measurement bar), $.5 \mathrm{~cm}$ in diam $x$ $21.2 \mathrm{~cm}$ in length, which could be rotated by the observer about a central axis parallel to the observer's straight-ahead line of sight. The plane of rotation of the measurement bar was parallel both to the observer's frontal plane and to the plane of the perceived tilt of the luminous rod-and-frame stimuli. Centered behind this bar was a vertical metal plate which tactually provided the observer with a vertical reference. The rotatable measurement bar was not visible to the observer during the presentations of the rod-and-frame illusion. and all of the observer's adjustments of this bar were made by touch. The adjustment by the observer of the measurement bar was read by the experimenter from an indicator located outside of the observation booth.

Observers. The observers were 47 women and 25 men, who partially satisfied a requirement of an introductory psychology course by their participation in the experiment. All had an acuity of $20 / 20$, both near and far, and a stereoacuity of $18^{\prime \prime}$ of arc as measured with a Keystone orthoscope.
Procedure. Before entering the observation booth. the observer received general instructions regarding his tasks. using a model of the rod-and-frame stimuli and also a model of the measurement bar. In addition, specific instructions were given to the observer during the course of the experiment. One-third of the observers were assigned randomly to the experimental situation in which the two frames were presented simultaneously, one-third to the experimental situation with the near frame only and one-third to the experimental situation with the far frame only. A trial consisted of the presentation of the single rod at one of the three stereoscopic distances in one of the above experimental situations. Thus, each observer was presented with three trials, with the rod at a different stereoscopic position on each trial. The order of presenting the three stereoscopic positions of the rod was systematically varied between observers.

Each observer on each trial had several tasks. For the perceived-tilt judgments. the observer was asked to adjust the tilt measuring bar (using the right hand) to indicate at different times the tilt that he perceived in the rod and in the sides of the frame or frames. Two tilt judgments were obtained for the rod and for the frame with each trial. Also, the observer was asked to estimate verbally in feet or inches. or in some combination of feet and inches. the perceived distance of the rod or of the frame or frames from his eyes. The order in which the observer made the judgments of perceived tilt and perceived distance and the order in which the judgments were completed for the rod and for the frame or frames on a trial was varied systematically between observers.

\section{Results}

A summary of the perceived tilt of the rod for each of the stereoscopic positions of the rod, for each of the three experimental situations (single frame near, single frame far, or two frames) is given in Table 1. A positive value in Table 1 indicates that the physically vertical rod was perceived as tilted in a counterclockwise direction and a negative value indicates that it was perceived as tilted in a clockwise direction. For each of the three situations, the near frame would tend to make the rod appear to be tilted clockwise (-) and the far frame would tend to make the rod appear to be tilted counterclockwise $(+)$.

Some of the data are skewed, as is indicated by the large differences that sometimes occur between the means and the medians. For this reason, the statistical significance of changes in the magnitude of the illusion within an experimental situation was tested by a rank-order analysis. In determining the rank order of the perceived tilt of the rod for the three stereoscopic positions of the rod, the largest algebraic value of the three responses (with each response the average of two adjustments), for a particular observer in a particular situation, was given the rank of 3 with the smallest given the rank of 1 . The magnitude of the resulting mean ranks, as a function of the stereoscopic position of the rod, and the statistical significance of the differences between mean ranks are shown in the table.

It is clear from Table 1 that a definition of the rod-and-frame illusion in terms only of the retinal orientations of the rod and frame is inadequate. This is shown by the induction changes that clearly occurred as a function of the stereoscopic position of 
Table 1

Perceived Tilt (Degrees) of Rod as a Function of Stereoscopic Position of Rod and Position and Number of Frames Present

\begin{tabular}{|c|c|c|c|c|c|c|c|c|c|}
\hline & \multicolumn{3}{|c|}{ Single, Near Frame } & \multicolumn{3}{|c|}{ Single, Far Frame } & \multicolumn{3}{|c|}{ Two Frames } \\
\hline & $\begin{array}{l}\text { Rod } \\
\text { Near } \\
\end{array}$ & $\begin{array}{c}\text { Rod } \\
\text { Middle }\end{array}$ & $\begin{array}{r}\text { Rod } \\
\text { Far } \\
\end{array}$ & $\begin{array}{l}\text { Rod } \\
\text { Near }\end{array}$ & $\begin{array}{c}\text { Rod } \\
\text { Middle }\end{array}$ & $\begin{array}{l}\text { Rod } \\
\text { Far }\end{array}$ & $\begin{array}{l}\text { Rod } \\
\text { Near }\end{array}$ & $\begin{array}{l}\text { Rod } \\
\text { Middle }\end{array}$ & $\begin{array}{l}\text { Rod } \\
\text { Far }\end{array}$ \\
\hline $\begin{array}{l}\text { Mean } \\
\text { Median } \\
\text { SD }\end{array}$ & $\begin{array}{r}-4.1 \\
-3.5 \\
4.5\end{array}$ & $\begin{array}{r}-3.0 \\
-3.0 \\
4.2\end{array}$ & $\begin{array}{r}-2.7 \\
-2.8 \\
3.5\end{array}$ & $\begin{array}{r}+1.8 \\
.0 \\
3.4\end{array}$ & $\begin{array}{r}+2.8 \\
+.8 \\
4.4\end{array}$ & $\begin{array}{r}+5.3 \\
+4.5 \\
4.9\end{array}$ & $\begin{array}{r}-2.4 \\
-1.8 \\
5.0\end{array}$ & $\begin{array}{r}-.2 \\
.0 \\
4.4\end{array}$ & $\begin{array}{r}+4.4 \\
+4.2 \\
5.0\end{array}$ \\
\hline Mean Rank & $\begin{array}{r}1.69 \\
x_{r}^{2}=3.30\end{array}$ & $\begin{array}{r}2.23 \\
\mathrm{~d} f=2\end{array}$ & $\begin{array}{r}2.08 \\
p>.05\end{array}$ & $\begin{array}{r}1.52 \\
x_{\mathbf{r}}^{2}=16.43\end{array}$ & $\begin{array}{r}1.83 \\
\mathrm{df}=2\end{array}$ & $\begin{array}{c}2.65 \\
p<.001\end{array}$ & $\begin{array}{r}1.52 \\
\chi_{\mathbf{r}}^{2}=18.14\end{array}$ & $\begin{array}{r}1.79 \\
\mathrm{df}=2\end{array}$ & $p<\begin{array}{c}2.69 \\
p .001\end{array}$ \\
\hline
\end{tabular}

Note-Positive value indicates physically vertical rod perceived to be tilted counterclockwise; negative value clockwise. Physical orientation of near frame, $+15 \mathrm{deg}$; far frame, $-15 \mathrm{deg}$.

the rod for the situation in which a single frame was presented at the far distance and for the situation in which the two frames were presented simultaneously. If the induction effects were determined by retinal position only, changes in the illusion as a function of the stereoscopic position of the rod would not have occurred.

On the other hand, consider the results expected if the effectiveness of the induction from a particular frame decreased as the rod was increasingly displaced stereoscopically from that frame. In the case of the single near frame, the clockwise $(-)$ perceived tilt of the physically vertical rod expected from the rod-and-frame illusion would become increasingly less negative as the rod was placed stereoscopically increasingly behind the frame. This result occurred although it was not significant as determined by the rank-order analysis shown in Table 1. In the case of the single far frame, the clockwise $(+)$ perceived tilt of the physically vertical rod expected from the rod-and-frame illusion would be expected to decrease as the rod was placed stereoscopically in front of the frame. As indicated in Table 1, this decrease occurred, and according to the analysis by ranks it was statistically significant. In the case of the two frames presented simultaneously, the frame at the plane of the rod would be expected to contribute a greater induction effect than the frame displaced in depth from the rod. It follows that the perceived tilt of the rod should be negative when the rod was located stereoscopically at the distance of the near frame, positive when the rod was stereoscopically at the distance of the far frame, and intermediate in value when stereoscopically between the two frames in depth. These expectations are in agreement with the results and, as indicated in the table, the changes in the illusion as a function of the stereoscopic position of the rod are statistically significant.

The decrease in the illusion shown in Table 1, for the situations in which only one frame was presented, is greater for the stereoscopic displacements of the rod in front of the far frame as compared with the equal stereoscopic displacements of the rod behind the near frame. This asymmetry in the depth adjacency effect is to be expected only if the strength of the absolute tilt cue for the rod had decreased with the increasing convergence distance of the rod from the observer. This hypothesized variation in the strength of the absolute tilt cue with distance is consistent with the smaller illusion obtained for the near as compared with the far frame when the rod and single frame were at the same distance (absolute medians of $3.5^{\circ}$ and $4.5^{\circ}$, respectively). Although this difference was not significant at the .05 level $(t=1.61$, $\mathrm{df}=46)$, as indicated by a randomization test for two independent samples, its validity tends to be supported by the similar results obtained with the simultaneous presentations of the two frames. In this latter situation, the absolute median values of $1.8^{\circ}$ and $4.2^{\circ}$ obtained when the rod and frame were at the same near or far distance was significantly different at the .025 level (one-tailed Wilcoxon matched-pairs test, $T$ $=50.5$ ). It seems that an explanation of the details of the results of the present experiment in terms of a conflict between absolute and relative cues to tilt is at least tenable.

The perceived tilt of the frame or frames is summarized in Table 2. Each mean in Table 2 is the average of 24 scores, one from each observer with each score the average of six tilt judgments, two judgments of which were obtained on each of three trials. The results from the three trials (rod near, rod middle, or

\section{Table 2}

Perceived Tilt (Degrees) of Frame as a Function of Distance of Frame and Number of Frames Present

\begin{tabular}{lccccc}
\hline & \multicolumn{2}{c}{ Single Frame Only } & & \multicolumn{2}{c}{ Two Frames } \\
\cline { 2 - 3 } \cline { 5 - 6 } & Near & Far & & Near & Far \\
& Frame & Frame & Frame & Frame \\
\hline Mean & +15.9 & $-19.8^{* *}$ & +15.3 & $-18.0^{*}$ \\
Median & +14.9 & -19.8 & +14.0 & -16.0 \\
SD & 5.4 & 6.5 & 6.2 & 6.8 \\
\hline
\end{tabular}

Note-Positive value indicates frame perceived to be tilted counterclockwise; negative value clockwise. Physical orientation of near frame, +15 deg; far frame, $-15 \mathrm{deg}$.

*Difference from -15 deg significant at .0S level.

**Difference from -15 deg significant at .01 level. 
Table 3

Reported Distance (Converted to Centimeters) of Rod as a Function of Its Stereoscopic Distance

\begin{tabular}{|c|c|c|c|c|c|c|c|c|c|}
\hline & \multicolumn{3}{|c|}{ Single, Near Frame } & \multicolumn{3}{|c|}{ Single, Far Frame } & \multicolumn{3}{|c|}{ Two Frames } \\
\hline & $\begin{array}{r}\text { Rod } \\
\text { Near }\end{array}$ & $\begin{array}{c}\text { Rod } \\
\text { Middle }\end{array}$ & $\begin{array}{l}\text { Rod } \\
\text { Far }\end{array}$ & $\begin{array}{l}\text { Rod } \\
\text { Near } \\
\end{array}$ & $\begin{array}{c}\text { Rod } \\
\text { Middle }\end{array}$ & $\begin{array}{l}\text { Rod } \\
\text { Far }\end{array}$ & $\begin{array}{l}\text { Rod } \\
\text { Near } \\
\end{array}$ & $\begin{array}{c}\text { Rod } \\
\text { Middle }\end{array}$ & $\begin{array}{l}\text { Rod } \\
\text { Far } \\
\end{array}$ \\
\hline $\begin{array}{l}\text { Mean } \\
\text { Median } \\
\text { SD }\end{array}$ & $\begin{array}{r}92.7 \\
62.2 \\
110.3\end{array}$ & $\begin{array}{r}156.4 \\
91.4 \\
287.1\end{array}$ & $\begin{array}{l}168.9 \\
114.3 \\
285.3\end{array}$ & $\begin{array}{l}64.3 \\
61.0 \\
25.6\end{array}$ & $\begin{array}{l}90.5 \\
91.4 \\
31.7\end{array}$ & $\begin{array}{r}125.0 \\
114.3 \\
71.0\end{array}$ & $\begin{array}{l}82.6 \\
78.6 \\
30.8\end{array}$ & $\begin{array}{r}111.2 \\
91.4 \\
41.4\end{array}$ & $\begin{array}{r}165.8 \\
152.4 \\
73.2\end{array}$ \\
\hline Mean Rank & $\begin{array}{r}1.10 \\
\chi_{r}^{2}=34.15\end{array}$ & $\begin{array}{r}2.13 \\
\mathrm{df}=2\end{array}$ & $\begin{array}{c}2.77 \\
\mathrm{p}<.001\end{array}$ & $\begin{array}{r}1.08 \\
\chi_{r}^{2}=34.59\end{array}$ & $\begin{array}{r}2.17 \\
\mathrm{df}=2\end{array}$ & $\begin{array}{c}2.75 \\
\mathrm{p}<.001\end{array}$ & $\begin{array}{r}1.15 \\
\chi_{r}^{2}=38.03\end{array}$ & $\begin{array}{r}1.94 \\
\mathrm{df}=2\end{array}$ & $\begin{array}{c}2.92 \\
\mathrm{p}<.001\end{array}$ \\
\hline
\end{tabular}

rod far) for a particular experimental situation (single frame near, single frame far, or two frames) were combined in forming Table 2 , since a rank-order analysis did not indicate that the judgments of the frame orientation differed as a function of the stereoscopic position of the rod. The average perceived tilts of the frames from the vertical are approximately equal to the physical tilts for the near frame but are somewhat overestimated for the far frame. It is clear that the error in the perceived tilt of the rod evidenced in many of the conditions in Table 1 cannot be attributed to a tendency for the frame or frames to appear to have a tilt less than the physical tilt.

Summaries of the verbal reports of distance of the rod and frame converted to centimeters are given in Tables 3 and 4, respectively. Clearly, the binocular cues were effective in determining perceived depth between objects and the perceived distances of the objects from the observer. It will be noted, consistent with the results obtained in previous research (Gogel, 1974; Gogel \& Koslow, 1972), that displacing the rod stereoscopically behind the single frame usually resulted in a decrease in the reported distance of the frame as well as an increase in the reported distance of the rod. Conversely, displacing the rod in front of the single frame usually increased the reported distance of the frame and decreased the reported distance of the rod. In other words, the stereoscopic displacement of the test object modified the apparent distance of the induction as well as the test object.

\section{EXPERIMENT II}

The use of the tactile measure of perceived tilt in Experiment I differs from the usual method of measuring the rod-and-frame illusion. Usually, in studies of the rod-and-frame illusion, the observer is asked to adjust the rod to the apparent vertical, and the deviation of this adjustment from the physical vertical is considered to be a measure of the illusion. The question answered by the use of the tactile measure is, "What is the average (or median) visual perception of tilt that is produced by a particular rod-frame stimulus?" The question answered by an adjustment to the apparent vertical is, "What is the average or median physical tilt of the rod that will produce a perception of a vertical rod in the presence of a frame of a particular physical tilt?" If the illusion is defined as a difference between a stimulus and a perception, i.e., as an error in perception, the two methods provide equally acceptable, although not necessarily completely equivalent, measures of the illusion. An advantage of the tactile over the usual method is that it can be used to provide a measure of the perceived tilt of the frame as well as of the rod. A disadvantage of the tactile method is that it assumes that a visual perception of tilt can be measured validly by a tactual perception of tilt. Experiment II examines this assumption by measuring visual tilt using the tactile method in a situation in which there are many visual cues to the tilt of the object. It is assumed that in this multicue situation, visually perceived and

Table 4

Reported Distance (Converted to Centimeters) of Frames as a Function of Their Physical Distance

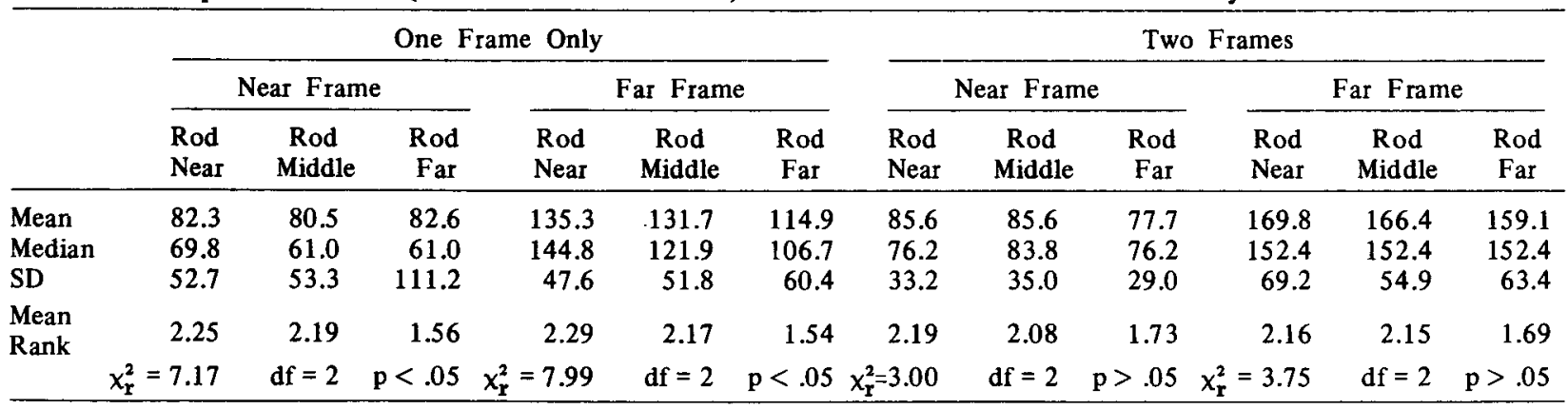


physical tilt are proportional. If this assumption is correct, the results obtained in Experiment II can be used to express the relationship between the visual and tactual perception of tilt. This relationship can then be used to evaluate the tactile measurement of the rod-and-frame illusion in Experiment $I$.

\section{Method}

Apparatus. The frame or rod figures for Experiment II were separately painted (drawn) on white disks, with the disks subtending a visual angle of $30^{\circ} 15.3^{\prime}$ and located at a distance of $123.0 \mathrm{~cm}$ from the observer. The rod was always black, whereas two parallel sides of the frame were black and the remaining two sides of the frame were red in order to identify for the observer the sides (black) that were to be judged by the observer for tilt. The visual angular size of the line representing the rod was $8^{\circ} 5.5^{\prime}$ in height and $14.0^{\prime}$ in thick ness. The visual angular size of the representation of the square frame was $10^{\circ} 19.1^{\prime}$ on a side, and the square was formed by lines whose thickness subtended $22.4^{\prime}$ of visual angle. By rotating a disk around its center, the experimenter presented the rod drawing at $0.0^{\circ}, 2.0^{\circ}, 6.0^{\circ}, 11.2^{\circ}$. or $33.8^{\circ}$ of tilt and the black sides of the frame drawing at $0.0^{\circ}, 11.2^{\circ}, 22.5^{\circ}, 33.8^{\circ}$, or $45.0^{\circ}$ in either direction from the vertical. This resulted in nine physical tilts of the rod drawing and nine of the frame drawing to be judged by the observer.

The disk containing a rod or frame drawing was suspended vertically, with its lowest portion $.75 \mathrm{~cm}$ above a table. The top of the table was $34.0 \mathrm{~cm}$ below the observer's eyes, and the center of a disk was on the primary line of sight. The tabletop was $156.6 \mathrm{~cm}$ long and $111.5 \mathrm{~cm}$ wide and was in an area $125 \mathrm{~cm}$ wide $\times 200 \mathrm{~cm}$ long. with the area enclosed on the sides and back by black curtains. The front surface enclosing the area was formed by the front wall of the observation booth, and the observer's view of the enclosure was restricted to a $114^{\circ}$ visual field by a $30.7-\mathrm{cm}$ square aperture located in the front wall of the observation booth. The enclosure was illuminated by a number of diffused light sources, with the tabletop and the white disks containing the stimuli evenly illuminated. The booth from which the stimuli were viewed was identical to that of Experiment 1, except that no light adaptation surface was used in Experiment II. As in Experiment I, the tilt indicator device (the measuring bar) was used by the observer to indicate the perceived tilt of the rod and the perceived tilt of the black sides of the square frame. The observer received general instructions regarding his tasks, using a model of the white disks and of the tilt indicator device before entering the observation booth. and more specific instruction thereafter.

Observers. The observers were 18 men and 18 women, who partially satisfied a requirement of an undergraduate psychology course by their participation in the experiment. None had participated in Experiment I. All observers had a visual acuity of $20 / 20$, both near and far, and a stereoscopic acuity of $18^{\prime \prime}$ of arc as measured with a Keystone orthoscope.

\section{Results}

The rod and frame drawings were presented successively to each observer. Half of the observers judged the nine physical tilts of first the rod and then the frame, with this order reversed for the remaining observers. The order in which the nine different magnitudes of tilt were presented differed between observers. Two tilt judgments obtained by tactually adjusting the measurement bar were obtained with each observer for each physical tilt of the rod or frame. The average of these two responses constituted a tilt score, with the average of the 36 tilt scores (one from each observer) shown in Figure 5. The results in Figure 5 would fall on the solid line if the adjusted tilt of the measurement bar were identical to the physical tilt of the rod and the frame. It will be noted that the average tilt scores for the rod and for the frame are very similar within the range of physical tilts common to these two objects. Tactile tilt seems to be a relatively unbiased measure of perceived visual tilt, at least for perceived tilts between approximately $\pm 15^{\circ}$. For larger counterclockwise perceived tilts, tactile tilt tends to underestimate perceived visual tilt, with this underestimation increasing the more the visual stimulus deviates from the vertical. It seems, from the results of Experiment II, that the tactile method of measuring visually perceived tilt in Experiment I was valid within the range of perceived tilts being measured.

\section{DISCUSSION}

The situation in which two frames of opposite physical tilt were simultaneously presented, one at a near and the other at a far distance, provides clear support for the adjacency principle as applied to induced tilt. The situation in which the rod was displaced in front of the single far frame, but less clearly the situation in which the rod was displaced behind the single near frame, also provides support for a factor of depth adjacency. The results from Experiment I parallel those obtained from induced motion (Gogel \& Koslow, 1971, 1972) and from induced size (Gogel, 1974). In all three types of induction (except for the nonsignificant changes resulting from displacing the test object behind the

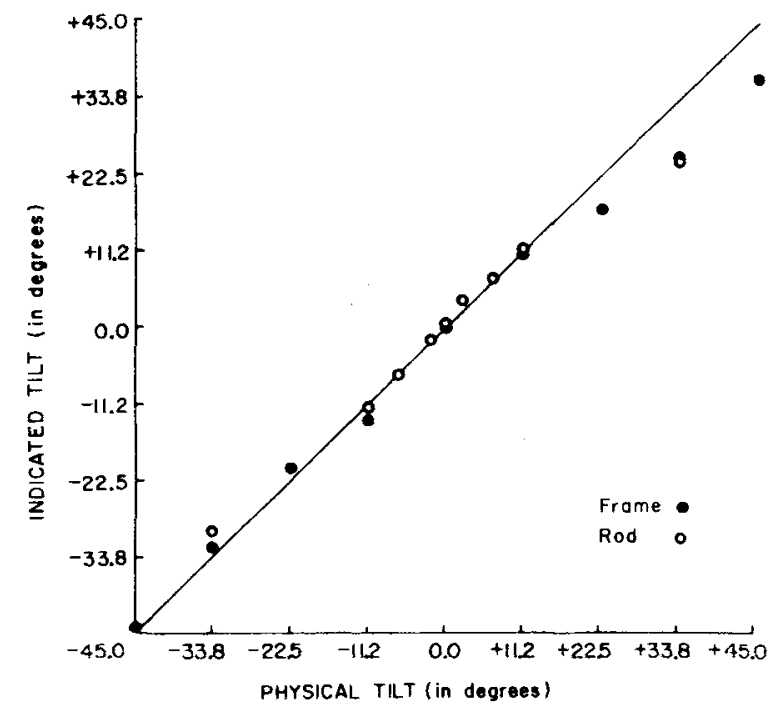

Figure 5. Relation between tilt of the measuring bar adjusted tactually and physical tilt of the rod and frame, with the rod and frame viewed under multicue conditions. 
induction object), the largest induction effects are obtained when the test and induction objects were most adjacent in apparent depth.

In any induction situation, the induction object modifies the perceived characteristics of the test object from that which would have occurred had the induction object been absent. It follows that perceptual induction can be analyzed as involving a conflict between the induction factor and the determiners of the perception in the absence of the induction object. Essentially, what is proposed is a two-factor theory of illusions, with the induction factor (the relative cue) and the noninduction factor (the absolute cue) both contributing to the perception. The perception will be determined by the relative weight given to these two conflicting cues (Gogel, 1975). The effect of perceived separation of the test and induction objects on the strength of the relative cue is specified by the adjacency principle. The change in the strength of the absolute cue on the test object as a function of the position of the test object has not been specified in any general manner. In the present study, there is some suggestion that the strength of the noninduction factor decreased with increasing distance from the observer. This was used to explain the greater reduction in the illusion with crossed than with uncrossed disparity of the rod. Research will be required to determine whether the relation between the strength of the absolute cues and distance from the observer varies systematically with distance for a variety of cues and situations.

In addition to variations in the effectiveness of absolute tilt cues with stereoscopic displacement of the rod in front of as compared with behind the single frame. two other explanations of the asymmetry of the results obtained with the single-frame conditions are possible. Ore of these concerns the perceived size of the rod relative to the frame. Since the visual angle of the rod (and frame) was constant, the perceived size of the rod relative to the frame should have been greater when the rod was perceptually behind rather than in front of the frame. Green. Lawson, and Godek (1972) have proposed that the relative perceived sizes of the test and induction objects are important in explaining the asymmetrical effect of depth adjacency obtained with a single Ponzo illusion. Although this explanation seems most germane to induction effects involving perceived size, perhaps the same kind of explanation might apply to the rod-and-frame illusion. Another possible explanation of the asymmetry in the results from the single frame conditions is that the stereoscopic displacement of the rod in front of the single frame permitted the observer to disregard the frame, whereas the observer had to look through (attend to) the frame to see the rod when the rod was stereoscopically behind the frame. This attention variable has been found in a previous experiment to be capable of modifying adjacency effects to some extent (Gogel, 1967), and it is possible that it contributed to the results obtained from the single-frame conditions in the present experiment. It is unlikely, however, that variations in either perceived size or attention are able to explain completely the depth effects obtained with the simultaneous presentation of the two frames.

Implicit in most interpretations of the rod-andframe illusion is the assumption that the illusion occurs because the perceived tilt of the frame is less than its physical tilt (Asch \& Witken, 1948; Brosgole \& Cristal, 1967; Koffka, 1935; Witkin \&Asch, 1938). This type of interpretation seems to assume that the orientation of the rod with respect to the frame is perceived correctly, and, as a consequence, the perception of the frame as less tilted than its physical tilt results in the physically upright rod being perceived as tilted in a direction opposite to the physical tilt of the frame. This type of interpretation is not supported by the present study. The error in the perceived tilt of the rod in Experiment $I$ is not the result of the perceived tilt of the frame being less than its physical tilt. Instead, the frame was perceived to have a tilt that was at least as large as its physical tilt. Nevertheless, the physically vertical rod was perceived as tilted in a direction opposite to the physical tilt of the frame. It is as though the observer overestimated the angle between the rod and the side of the frame most nearly parallel to the rod. This overestimation of the angle is shown in Table 5 , which summarizes the perceived angles between the physically vertical rod and the sides of the frames tilted $\pm 15^{\circ}$ from the

Table 5

Computed Perceived Angle (Degrees) Between Rod and Frame in Experiment 1 as a Function of Number and Position of Frames and Stereoscopic Position of Rod

\begin{tabular}{|c|c|c|c|c|c|c|c|c|c|c|c|c|}
\hline & \multicolumn{12}{|c|}{$\begin{array}{l}\text { Angle Computed from Perceived Tilt of Rod and } \\
\text { One Frame Only }\end{array}$} \\
\hline & \multicolumn{3}{|c|}{ Near Frame } & \multicolumn{3}{|c|}{ Far Frame } & \multicolumn{3}{|c|}{ Near Frame } & \multicolumn{3}{|c|}{ Far Frame } \\
\hline & $\begin{array}{l}\text { Rod } \\
\text { Near }\end{array}$ & $\begin{array}{c}\text { Rod } \\
\text { Middle }\end{array}$ & $\begin{array}{l}\text { Rod } \\
\text { Far }\end{array}$ & $\begin{array}{l}\text { Rod } \\
\text { Near }\end{array}$ & $\begin{array}{l}\text { Rod } \\
\text { Middle }\end{array}$ & $\begin{array}{l}\text { Rod } \\
\text { Far }\end{array}$ & $\begin{array}{l}\text { Rod } \\
\text { Near }\end{array}$ & $\begin{array}{l}\text { Rod } \\
\text { Middle }\end{array}$ & $\begin{array}{c}\text { Rod } \\
\text { Far }\end{array}$ & $\begin{array}{l}\text { Rod } \\
\text { Near }\end{array}$ & $\begin{array}{c}\text { Rod } \\
\text { Middle }\end{array}$ & $\begin{array}{l}\text { Rod } \\
\text { Far }\end{array}$ \\
\hline Mean & 20.8 & 18.5 & 18.1 & 22.6 & 22.6 & 24.9 & 17.3 & 15.2 & 11.5 & 15.9 & 17.8 & 22.2 \\
\hline Median & 18.0 & 19.5 & 17.8 & 23.0 & 20.8 & 25.2 & 16.2 & 14.0 & 10.5 & 16.2 & 17.8 & 20.5 \\
\hline SD & 8.3 & 5.5 & 5.5 & 7.9 & 7.4 & 8.9 & 9.5 & 7.3 & 6.7 & 6.9 & 7.3 & 9.6 \\
\hline
\end{tabular}


vertical, as computed from the measurements of the perceived tilt of the rod and of the perceived tilt of the frame. Perhaps the rod-and-frame illusion obtained in the present study can be classified with those illusions which involve errors in the overestimation of angles where such angles would have been formed had the lines been extended (see Fisher, 1969).

\section{REFERENCES}

Asch, S. E., \& Witkin, H. A. Studies in space orientation. I. Perception of the upright with displaced visual fields and with body tilted. Journal of Experimental Psychology, 1948, 38, 455-477.

Beh, H. C., Wenderoth, P. M., \& Purcell, A. T. The angular function of a rod-and-frame illusion. Perception \& Psychophysics, 1971, 9, 353-355.

Brosgole, L., \& Cristal, R. M. The role of phenomenal displacement on the perception of the visual upright. Perception \& Psychophysics, 1967, 2, 179-188.

Cohen, W., \& Tepas, D. Temporal factors in the perception of verticality. American Journal of Psychology, 1958, 71, $760-763$.

Fisher, G. H. An experimental study of angular subtension. Quarterly Journal of Experimental Psychology, 1969, 21, 356-366.

Gogel, W. C. Cue enhancement as a function of task-set. Perception \& Psychophysics, 1967, 2, 455-458.

Gogel, W. C. The adjacency principle and three-dimensional visual illusions. In J. C. Baird (Ed.). Human space perception: Proceedings of the Dartmouth Conference. Psychonomic Monograph Supplement, 1970, 3(13, Whole No. 45), 1970.
Gogel, W. C. Depth adjacency and cue effectiveness. Journal of Experimental Psychology, 1972, 92, 176.181.

GoGEL, W. C. Relative motion and the adjacency principle. Quarterly Journal of Experimental Psychology, 1974, 26. 425-437.

GoGkL, W. C. Depth adjacency and the Ponzo illusion. Perception \& Psychophysics. 1975, 17, 125-132.

Gogel, W. C., \& KosLow, M. The effect of perceived distance on induced movement. Perception \& Psychophysics, 1971, 10, $142 \cdot 146$.

Gogel, W. C., \& Kossow, M. The adjacency principle and induced movement. Perception \& Psychophysics, 1972, 11, 309-314.

Green, R. T., Lawson, R. B., \& Godek, C. L. The Ponzo illusion in stereoscopic space. Journal of Experimental Psychology, 1972, 95, 358-364.

KoffKA, K. Principles of Gestalt psychology. New York: Harcourt. Brace and Company, 1935.

NEAL, E. Visual localization of the vertical. American Journal of Psychology, 1926, 37, 287-291.

WIST, E. R. Mach bands and depth adjacency. Bulletin of the Psychonomic Society, 1974, 3, 97-99.

Wist, E. R., \& Susen, P. Evidence for the role of postretinal processes in simultaneous contrast. Psychologische Forschung, 1973, 36, 1-12.

Witkin, H. A. The perception of the upright. Scientific American. February 1959.

Wrtkın, H. A., \& Asch, S. E. Studies in space orientation. IV. Further experiments on perception of the upright with displaced visual fields. Joumal of Experimental Psychology. 1948, 38. 762-782.

(Received for publication January 8, 1975; revision received May 14,1975 .) 